\title{
Vibrational Analysis of All Terrain Bike [ATB] using FEM
}

\author{
Aishwary Mendke ${ }^{1}$, Suman Sharma ${ }^{2}$ \\ ${ }^{1}$ PG Student, Department of Mechanical Engineering, SIRT Indore, RGPV Bhopal \\ ${ }^{2}$ Professor and Head, Department of Mechanical Engineering, SIRT Indore, RGPV Bhopal
}

\begin{abstract}
Bicycles continue to be eliminate mode of transport for middle income families. This is because the bicycle is environment but required more people efforts. India is the largest producer of bicycles. Considering the rising fuels cost and pollution, the bicycle is considered ideal. These can be maintained at low costs. Since their inception bicycles have provided society with a good source of transportation, exercise which is good for human body, recreation and sport. New bicycle frames are generally motivated by weight and often incorporate the use of high performance materials. Energy is expended for propulsion and elastic deformation of the frame. Therefore a minimization of frame's total mass and deflection are essential. Most modern bicycle frames have simple form e.g. diamond shaped frame it was in 1895 after several remained basically unchanged since that time. The need for low load coupled with high strength has led to continuing trail and development of excellent materials for racing bicycles The solution to the pertaining problem is to switch to the most reliable and a proven tool of structural engineering; the Finite Element Method (FEM).
\end{abstract}

Keywords: All Terrain bike frame, Static start up, Steady state pedaling, vertical impact, Horizontal impact, Rear wheel braking

\section{Introduction}

The bicycle frame designed for analysis feature a traditional diamond frame design, consisting of a front and rear triangle. This design has been the industry standard for bicycle frame design for over one hundred years. The frame consists of a top tube, down tube, head tube, seat tube, seat stays, and chain stays as seen in Figure 1. The head tube of the frame holds the steerer tube of the fork, which in turn holds the front wheel. The top tube and down tube connect the head tube to the seat tube and bottom bracket. The seat tube holds the seat post, which holds the saddle. The bottom bracket holds the cranks, which hold the pedals. The seat stays and chain stays hold the rear dropouts, which connect the rear wheel to the frame. From that a size for a person with a height of normal person a frame was constructed. Throughout the years, frame building materials have evolved from what we now think as very primitive materials to space age materials which were unknown to our society 30 years ago. It is his improvement in materials which allowed to the greatest extent the evolution of the bicycle frame designs.

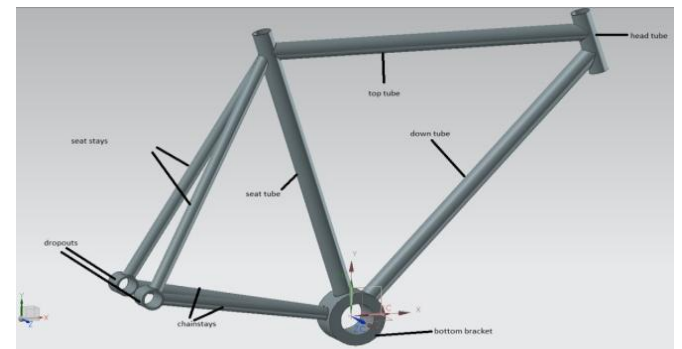

Figure 1: Tubing diagram of the bike frame

\section{Theoretical Analysis of Bike Frames}

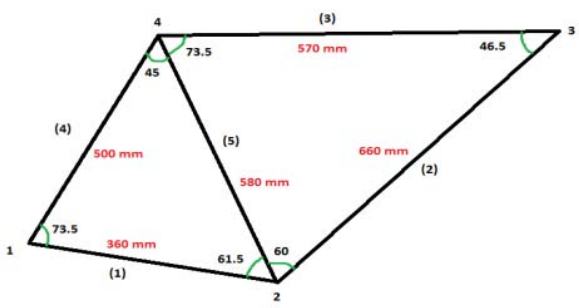

Figure 2: Bike frame truss

There are 7 steps involved in any finite element analysis. These steps are related to 3 phases, namely:

1. Preprocessing

2. Solution

3. Post processing

\section{Preprocessing Phase}

i. Discredited the bike frame into nodes and elements.

Each truss members is considered an element, and each joint connecting member is a node. Therefore, the given truss can be modeled with four nodes and five elements from figure 60. Table 6 clearly depicts the relationship between the elements and their corresponding nodes.

Table 1: The relationship between the elements and their corresponding nodes

\begin{tabular}{|c|c|c|c|}
\hline Element & Node $\mathrm{i}$ & Node $\mathrm{j}$ & $\Theta$ \\
\hline-1 & 1 & 2 & 349 \\
\hline-2 & 2 & 3 & 50 \\
\hline-3 & 3 & 4 & 0 \\
\hline-4 & 1 & 4 & 63 \\
\hline-5 & 2 & 4 & 110 \\
\hline
\end{tabular}

In general, two frames of reference are required to describe truss problems: a global coordinate system and a local frame of reference. A fixed global coordinate system, XY (1) to represent the location of each joint (node) and to keep track 


\section{International Journal of Science and Research (IJSR) \\ ISSN (Online): 2319-7064}

Index Copernicus Value (2015): 78.96 | Impact Factor (2015): 6.391

of the orientation of each member (element), using angles such as $\Theta ;(2)$ to apply the constraints and the applied loads in terms of their respective global components; and (3) to represent the solution - that is, the displacement of each joint in global directions. We will also need a local, or an elemental coordinate system $x y$, to describe the two-force member behavior of individual members (elements). The relationship between the local (element) descriptions and the global description is shown in figure 61.
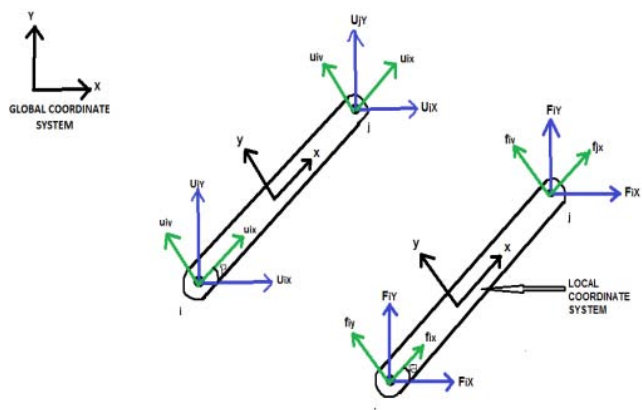

Figure 3: Relationship between local and global coordinates.

Note that local coordinate $\mathrm{x}$ points from node $\mathrm{i}$ toward $\mathrm{j}$

ii. Assume a solution that approximates the behavior of an element.

The average stresses in any two-force member are given by

$$
\sigma=F / A
$$

The average strain of the member can be expressed by

$$
\varepsilon=\Delta L / L
$$

Over the elastic region, the stress and strain are related by

Hooke's law,

$$
\sigma=E \varepsilon
$$

Combining Eqs. (a), (b) and (c) and simplifying, we have

$$
F=(A E / L) * \Delta L
$$

Equation (d) is similar to the equation of a linear spring, $\mathrm{F}=$ $\mathrm{kx}$. Therefore, a centrally loaded member of uniform cross section may be modeled as a spring with equivalent stress of

$$
\mathrm{Keq}=\mathrm{AE} / \mathrm{L}
$$

This equivalent stiffness constant will vary for individual material alloys and also for different dimensioned members of the same alloy. As there are 5 different elements in the bike truss so we will obtain 5 different stiffness constants for a single material alloy.

iii. Develop equations for elements.

The global displacements (UiX, UiYat node i and UjX, UjYat node $\mathrm{j}$ ) are related to the local displacements (uix, uiyat node $\mathrm{i}$ and ujx, ujyat node $\mathrm{j}$ ) according to the equations

$$
\begin{aligned}
& U_{i x}=u_{i x} \cos \theta-\mathrm{u}_{\mathrm{iy}} \sin \theta \\
& U_{i Y}=u_{i x} \sin \theta+\mathrm{u}_{\mathrm{iy}} \cos \theta \\
& U_{j X}=u_{j x} \cos \theta-\mathrm{u}_{\mathrm{jy}} \sin \theta \\
& U_{j Y}=u_{j x} \sin \theta+\mathrm{u}_{\mathrm{jy}} \cos \theta
\end{aligned}
$$

Now, equation (f) in matrix form,

$$
\{\mathrm{U}\}=[\mathrm{T}]\{\mathrm{u}\}
$$

Where

$$
\{U\}=\left(\begin{array}{l}
U_{i X} \\
U_{i Y} \\
U_{j X} \\
U_{j Y}
\end{array}\right),[T]=\left(\begin{array}{cccc}
\cos \theta & -\sin \theta & 0 & 0 \\
\sin \theta & \cos \theta & 0 & 0 \\
0 & 0 & \cos \theta & -\sin \theta \\
0 & 0 & \sin \theta & \cos \theta
\end{array}\right) \text {, and }\{u\}=\left(\begin{array}{l}
u_{i x} \\
u_{i y} \\
u_{j x} \\
u_{j y}
\end{array}\right)
$$

$\{U\}=$ displacements of nodes $\mathrm{i}$ and $\mathrm{j}$ with respect to the global $\mathrm{XY}$

$\{\mathrm{u}\}=$ displacements of nodes $\mathrm{i}$ and $\mathrm{j}$ with respect to the local xy frame of reference

$[\mathrm{T}]=$ transformation matrix that allows for transfer of local deformations to their respective global values

The local forces may be related according to the equations:

$$
\begin{aligned}
& F_{i x}=f_{i x} \cos \theta-f_{i y} \sin \theta \\
& F_{i Y}=f_{i x} \sin \theta+f_{i y} \cos \theta \\
& F_{j X}=f_{j x} \cos \theta-f_{j y} \sin \theta \\
& F_{j Y}=f_{j x} \sin \theta+f_{j y} \cos \theta
\end{aligned}
$$

Or, in matrix form,

$\{\mathrm{F}\}=[\mathrm{T}]\{\mathrm{f}\}(\mathrm{i})$

Where

$$
\{\mathrm{F}\}=\left(\begin{array}{c}
F_{i X} \\
F_{i Y} \\
F_{j X} \\
F_{j Y}
\end{array}\right)
$$

Are components of forces acting at nodes $\mathrm{i}$ and $\mathrm{j}$ with respect to global coordinates and

$$
\{\mathrm{f}\}=\left(\begin{array}{c}
f_{i x} \\
f_{i y} \\
f_{j x} \\
f_{j y}
\end{array}\right)
$$

Represent the local components of the forces at nodes $\mathrm{i}$ and $\mathrm{j}$. Here the displacements and the forces are zero in the local ydirection. This fact is simply because under the two-force assumption, the members can only be shortened along their longitudinal axis (local $\mathrm{x}$-axis). This fact also holds true for the internal forces that acts only in the local $\mathrm{x}$-direction. So the y-components of the displacements and forces equal to zero. The local internal forces and displacements are related through the stiffness matrix

$$
\left(\begin{array}{c}
f_{i x} \\
f_{i y} \\
f_{j x} \\
f_{j y}
\end{array}\right)=\left(\begin{array}{cccc}
k & 0 & -k & 0 \\
0 & 0 & 0 & 0 \\
-k & 0 & k & 0 \\
0 & 0 & 0 & 0
\end{array}\right)\left(\begin{array}{l}
u_{i x} \\
u_{i y} \\
u_{j x} \\
u_{j y}
\end{array}\right)
$$

where $\mathrm{k}=\mathrm{keq}=\mathrm{AE} / \mathrm{L}$, and using matrix form we can write $\{\mathrm{f}\}=[\mathrm{K}]\{\mathrm{u}\}(\mathrm{k})$ 


\section{International Journal of Science and Research (IJSR) \\ ISSN (Online): 2319-7064}

Index Copernicus Value (2015): 78.96 | Impact Factor (2015): 6.391

After substituting for $\{f\}$ and $\{u\}$ in terms of $\{F\}$ and $\{U\}$, we have

$$
[\mathrm{T}]-1\{\mathrm{~F}\}=[\mathrm{K}][\mathrm{T}]-1\{\mathrm{U}\}
$$

where $[\mathrm{T}]-1$ is the inverse of the transformation matrix [T] and is

$$
[\mathrm{T}]-1=\left(\begin{array}{cccc}
\cos \theta & \sin \theta & 0 & 0 \\
-\sin \theta & \cos \theta & 0 & 0 \\
0 & 0 & \cos \theta & \sin \theta \\
0 & 0 & -\sin \theta & \cos \theta
\end{array}\right)
$$

Multiplying both sides of eq. (1) by [T] and simplifying,

$$
\{\mathrm{F}\}=[\mathrm{T}][\mathrm{K}][\mathrm{T}]-1\{\mathrm{U}\}
$$

Substituting the values of the $[\mathrm{T}],[\mathrm{K}],[\mathrm{T}]-1$, and $\{\mathrm{U}\}$ matrices in eq. (n) and multiplying, we are left with

$$
\begin{gathered}
\left(\begin{array}{c}
F_{i X} \\
F_{i Y} \\
F_{j X} \\
F_{j Y}
\end{array}\right)=\mathrm{k} \\
\left(\begin{array}{cccc}
\cos ^{2} \theta & \sin \theta \cos \theta & -\cos ^{2} \theta & -\sin \theta \cos \theta \\
\sin \theta \cos \theta & \sin ^{2} \theta & -\sin \theta \cos \theta & -\sin ^{2} \theta \\
-\cos ^{2} \theta & -\sin \theta \cos \theta & \cos ^{2} \theta & \sin \theta \cos \theta \\
-\sin \theta \cos \theta & -\sin ^{2} \theta & \sin \theta \cos \theta & \sin ^{2} \theta
\end{array}\right) \\
\\
\left(\begin{array}{l}
U_{i X} \\
U_{i Y} \\
U_{j X} \\
U_{j Y}
\end{array}\right)
\end{gathered}
$$

Equation (o) expresses the relationship between the applied forces, the element stiffness matrix [K] (e), and the global deflection of the nodes of an arbitrary element. The stiffness matrix $[\mathrm{K}](\mathrm{e})$ for any member (element) of the truss is

$[\mathrm{K}](\mathrm{e})=$

$$
\left(\begin{array}{cccc}
\cos ^{2} \theta & \sin \theta \cos \theta & -\cos ^{2} \theta & -\sin \theta \cos \theta \\
\sin \theta \cos \theta & \sin ^{2} \theta & -\sin \theta \cos \theta & -\sin ^{2} \theta \\
-\cos ^{2} \theta & -\sin \theta \cos \theta & \cos ^{2} \theta & \sin \theta \cos \theta \\
-\sin \theta \cos \theta & -\sin ^{2} \theta & \sin \theta \cos \theta & \sin ^{2} \theta
\end{array}\right)
$$

By using eq. (p) different stiffness matrices are obtained for different elements which are made to assemble in the next step.

\section{iv. Assemble elements}

The global stiffness matrix is obtained by assembling, or adding together, the individual elements' matrices:

$[\mathrm{K}](\mathrm{G})=[\mathrm{K}](1 \mathrm{G})+[\mathrm{K}](2 \mathrm{G})+[\mathrm{K}](3 \mathrm{G})+[\mathrm{K}](4 \mathrm{G})+[\mathrm{K}](5 \mathrm{G})$

\section{Apply the boundary conditions and loads.}

The boundary conditions in accordance to the loading cases are incorporated in the global stiffness matrix. The external loads at the nodes and fixing of the nodes should be in accordance to boundary conditions.

$[\mathrm{K}](\mathrm{G})\{\mathrm{U}\}=\{\mathrm{F}\}$

\section{Solution Phase}

vi. Solve a system of algebraic equations simultaneously The displacement of the nodes is obtained on solving the above matrix with respect to the global coordinate system.

$$
\{\mathrm{U}\}=[\mathrm{K}]-(\mathrm{G})
$$

\section{Post Processing Phase}

vi. Obtain other information.

Reaction Forces

Reaction forces can be computed from:

$\{\mathrm{R}\}=[\mathrm{K}](\mathrm{G})\{\mathrm{U}\}-\{\mathrm{F}\}$

Internal Forces and Normal Stresses

The member internal forces fix and fjx, which are equal and opposite in direction, are

$$
\begin{aligned}
& \text { fix }=k(u i x-\text { ujx }) \\
& \text { fjx }=k(u j x-\text { uix })(q)
\end{aligned}
$$

The sum of fix and fjxis zero. For computing the internal forces in a given element, we must know the displacements of the element's end nodes, uix and ujx, with respect to the local coordinate system, $\mathrm{x}, \mathrm{y}$. the global displacements are related to the local displacements through a transformation matrix, according to eq. (g),

$\{\mathrm{U}\}=[\mathrm{T}]\{\mathrm{u}\}$

And the local displacements in terms of global displacements:

$\{\mathrm{u}\}=[\mathrm{T}]-1\{\mathrm{U}\}$

$$
\left(\begin{array}{l}
\boldsymbol{u}_{i x} \\
\boldsymbol{u}_{i y} \\
\boldsymbol{u}_{j x} \\
\boldsymbol{u}_{j y}
\end{array}\right)=\left(\begin{array}{cccc}
\cos \theta & \sin \theta & 0 & 0 \\
-\sin \theta & \cos \theta & 0 & 0 \\
0 & 0 & \cos \theta & \sin \theta \\
0 & 0 & -\sin \theta & \cos \theta
\end{array}\right)\left(\begin{array}{l}
U_{i x} \\
U_{i Y} \\
U_{j X} \\
U_{j Y}
\end{array}\right)
$$

Once the internal force in each member is computed, the normal stress in each member can be determined from the equation

$\sigma=$ internal force $/$ area $=\mathrm{f} / \mathrm{A}$

Or alternatively, normal stress can be calculated as

$\sigma=\mathrm{f} / \mathrm{A}=\mathrm{k}(\mathrm{uix}-\mathrm{ujx}) / \mathrm{A}=(\mathrm{AE} / \mathrm{L}) *(\mathrm{uix}-\mathrm{ujx}) / \mathrm{A}=\mathrm{E}(\mathrm{uix}-$ ujx/L)

\section{Modal Analysis}

Vibration analysis is made to be performed on all the 5 material alloy frames. No boundary condition is applied on the bike frames. Seat tube is supported so as to make the bike frames stable for the vibration test. When the simulation has finished the mode shapes are made visible. 


\subsection{Aluminum 6061-T}

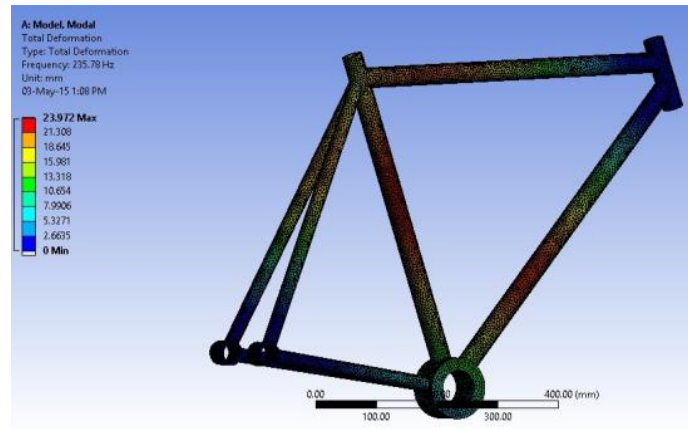

Figure 4: Mode 1, 235.78 Hz

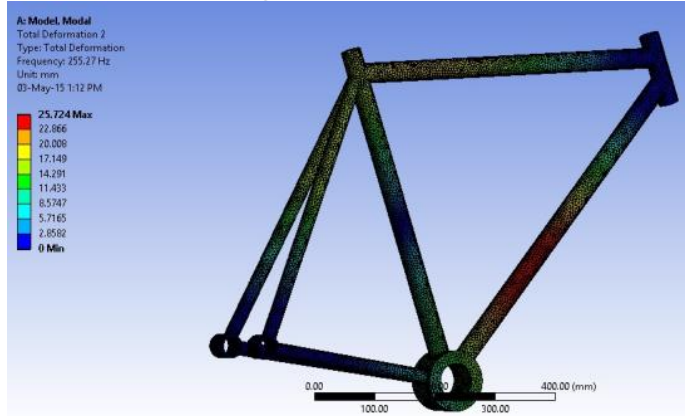

Figure 5: Mode 2, $255.27 \mathrm{~Hz}$

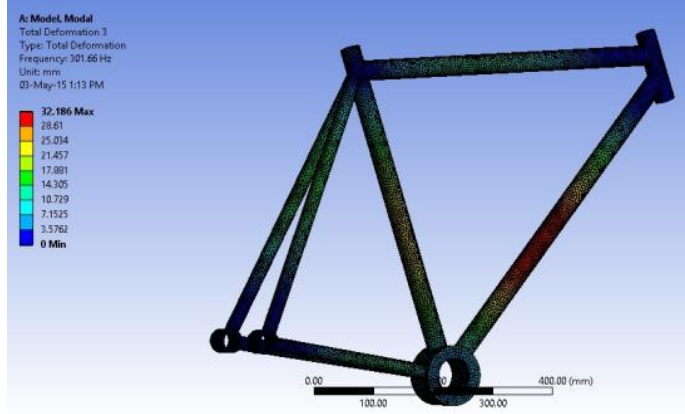

Figure 6: Mode 3, $301.66 \mathrm{~Hz}$

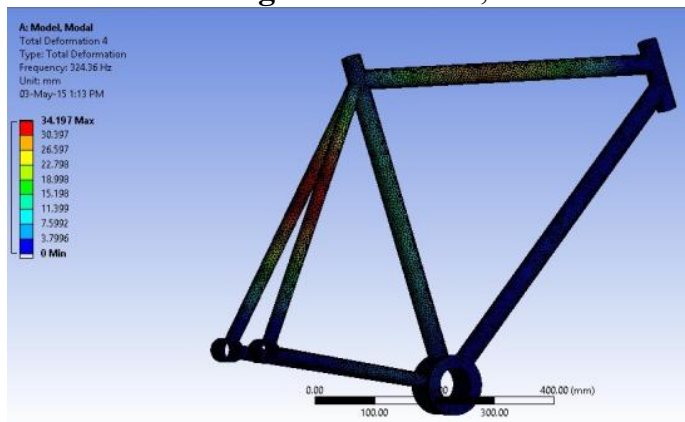

Figure 7: Mode 4, $324.36 \mathrm{~Hz}$

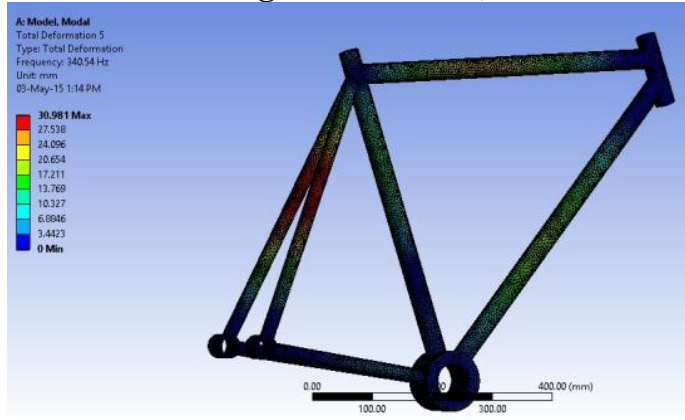

Figure 8: Mode 5, $340.54 \mathrm{~Hz}$

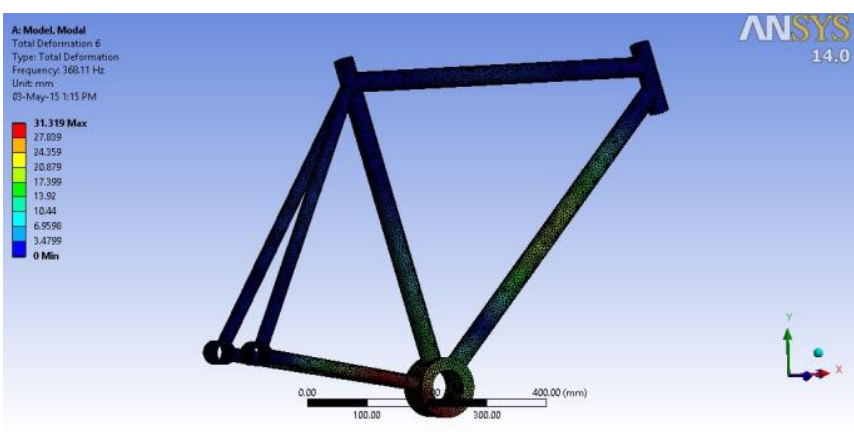

Figure 9: Mode 6, $368.11 \mathrm{~Hz}$

3.2 Aluminum 7005-T

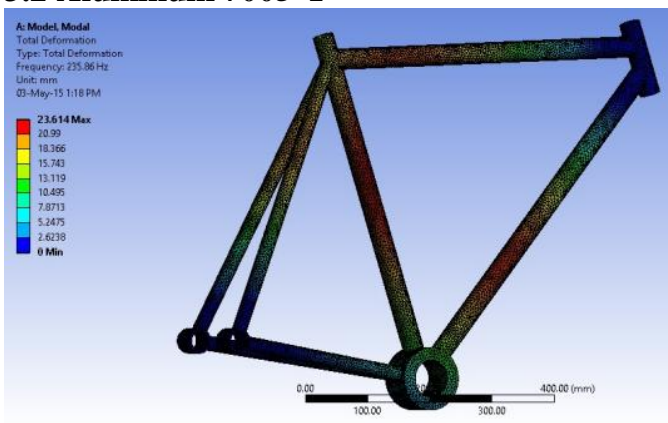

Figure 10: Mode 1, 235.86 Hz

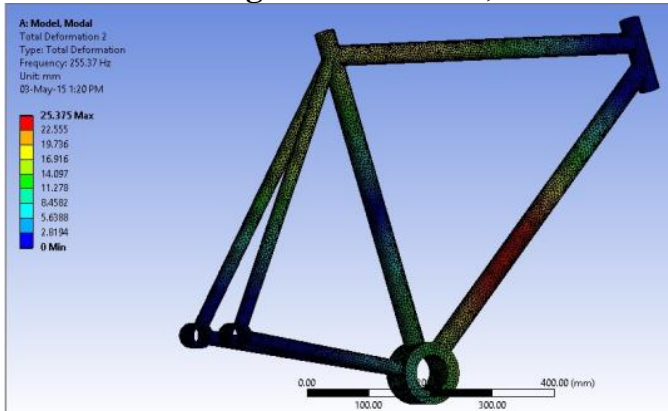

N

Figure 11: Mode 2, $255.37 \mathrm{~Hz}$

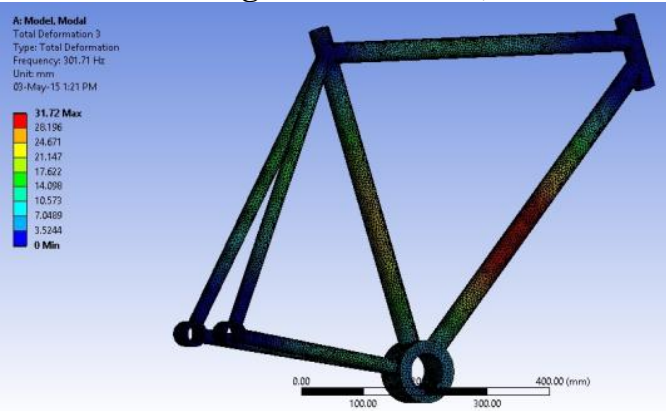

Figure 12: Mode $3,301.71 \mathrm{~Hz}$

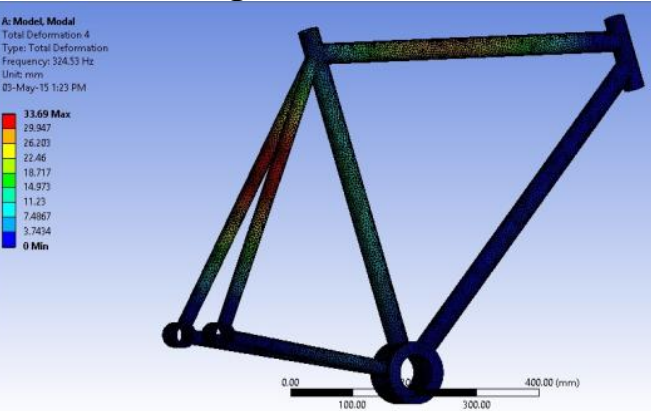

Figure 13: Mode 4, $324.53 \mathrm{~Hz}$

Volume 6 Issue 1, January 2017 www.ijsr.net 


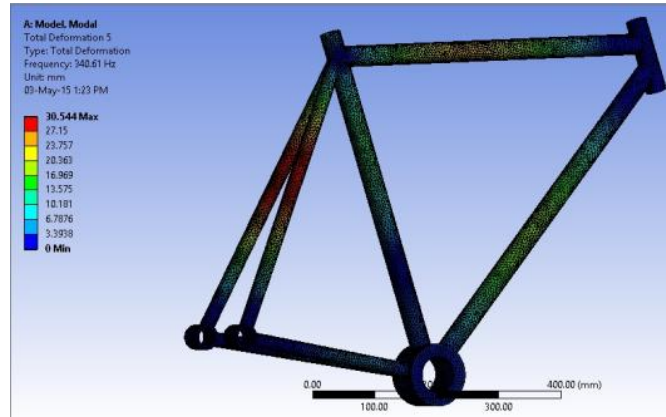

Figure 14: Mode 5, 340.61 Hz

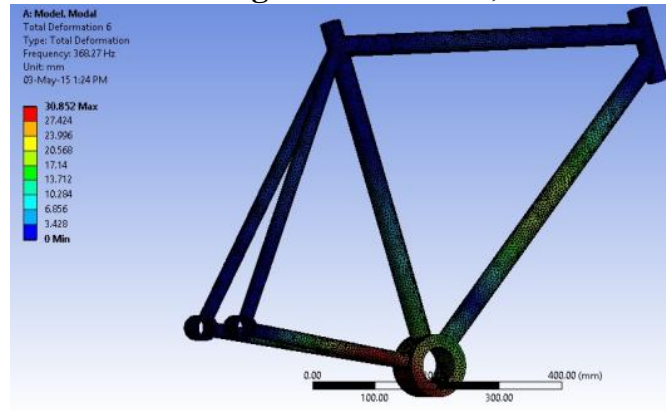

Figure 15: Mode 6, 368.27 Hz

3.3 Chromoly-4130

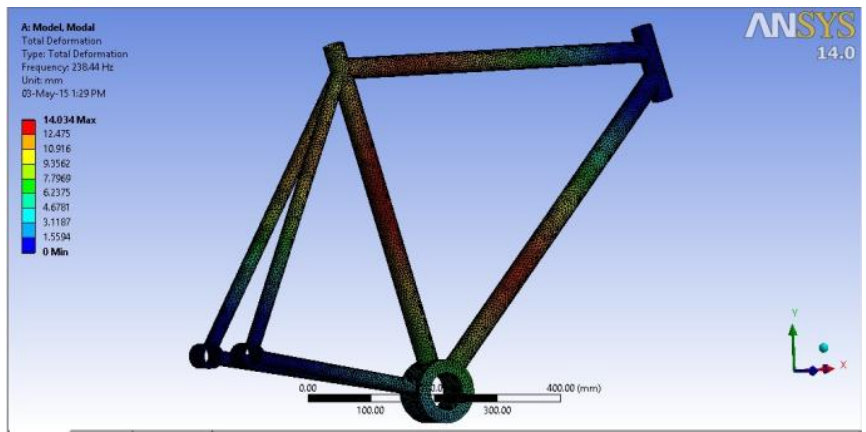

Figure 15: Mode 1, $238.44 \mathrm{~Hz}$

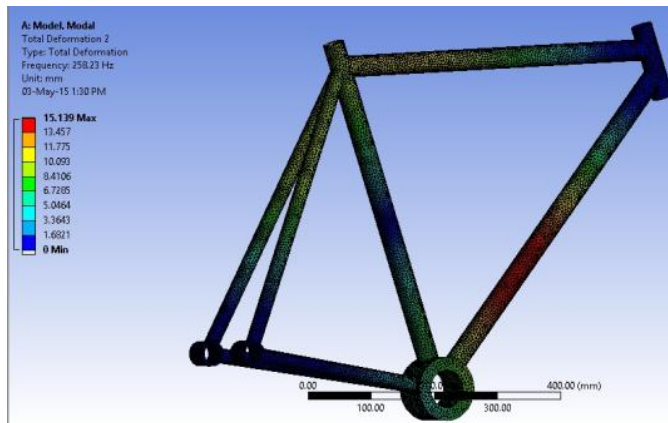

Figure 16: Mode 2, $258.23 \mathrm{~Hz}$

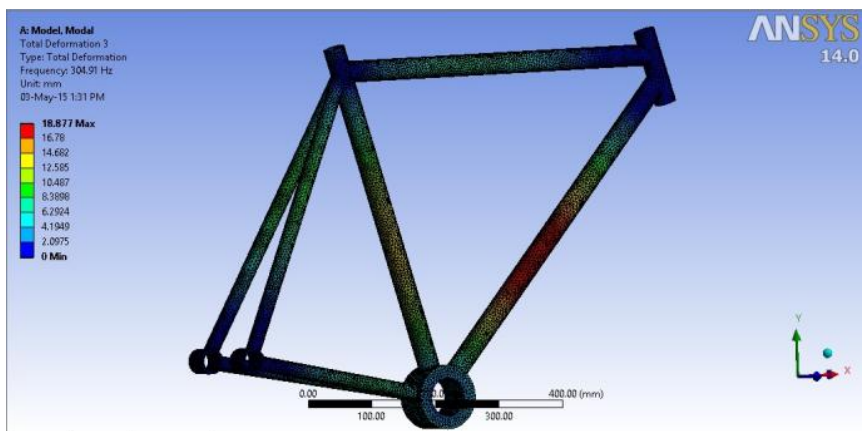

Figure 17: Mode 3, 304.91 Hz

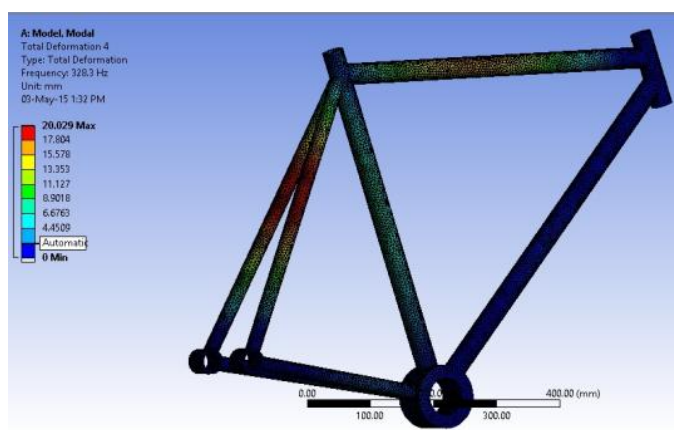

Figure 18: Mode 4, $328.3 \mathrm{~Hz}$

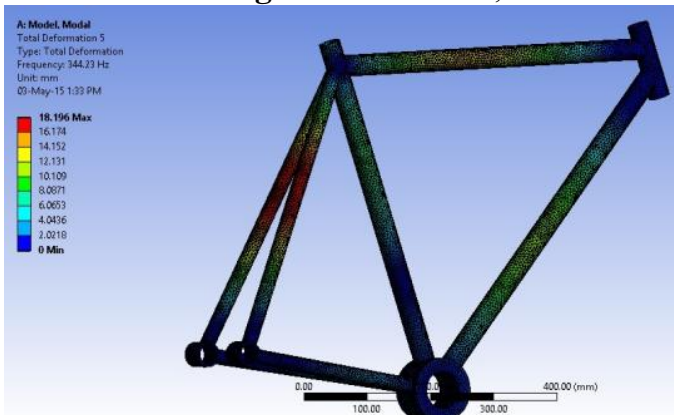

N

Figure 19: Mode 5, 344.23 Hz

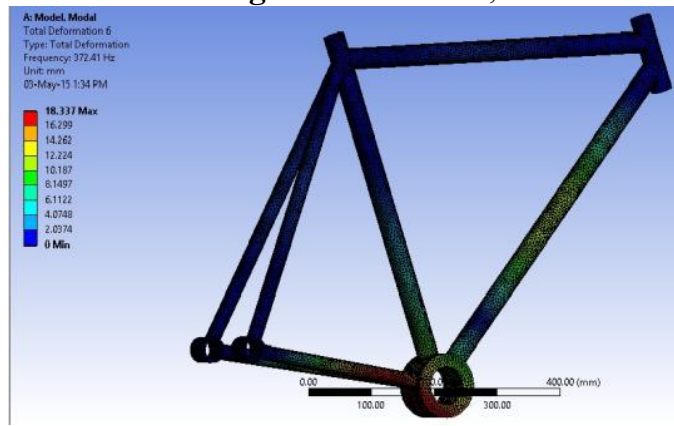

Figure 20: Mode 5, $372.41 \mathrm{~Hz}$

\subsection{Titanium-3Al-2.5V}

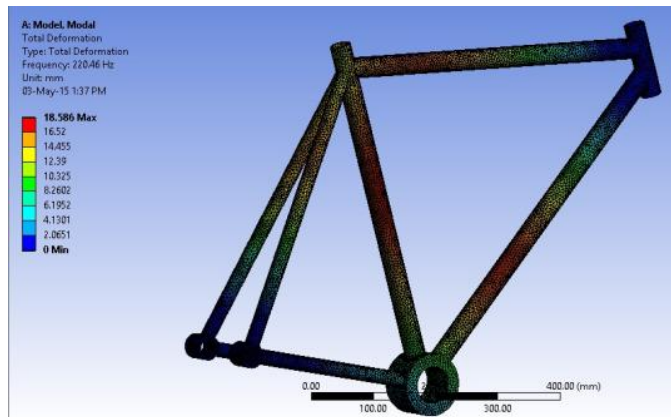

NN

Figure 21: Mode 1, 220.46 Hz

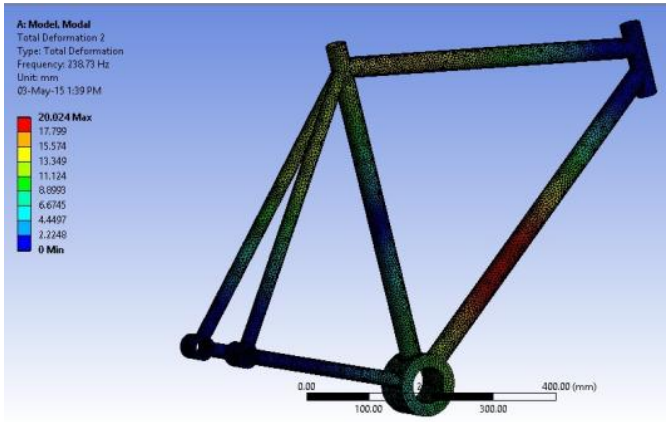

Figure 22: Mode 2, $238.73 \mathrm{~Hz}$

Volume 6 Issue 1, January 2017

www.ijsr.net 
International Journal of Science and Research (IJSR)

ISSN (Online): 2319-7064

Index Copernicus Value (2015): 78.96 | Impact Factor (2015): 6.391

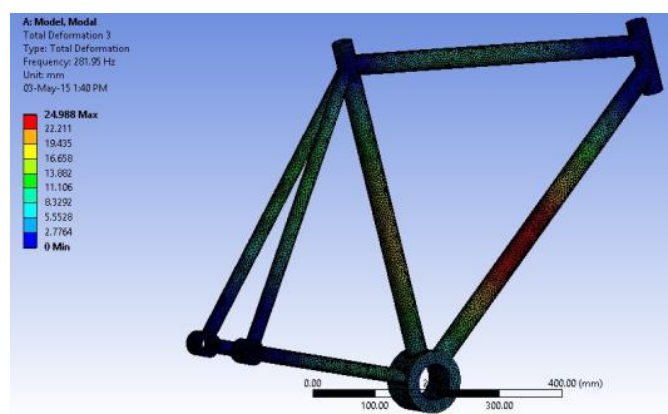

Figure 23: Mode 3, 281.95 Hz

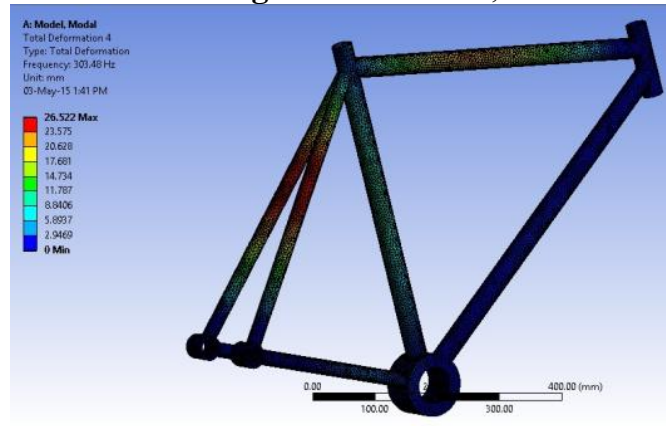

Figure 24: Mode 4, 303.48 Hz

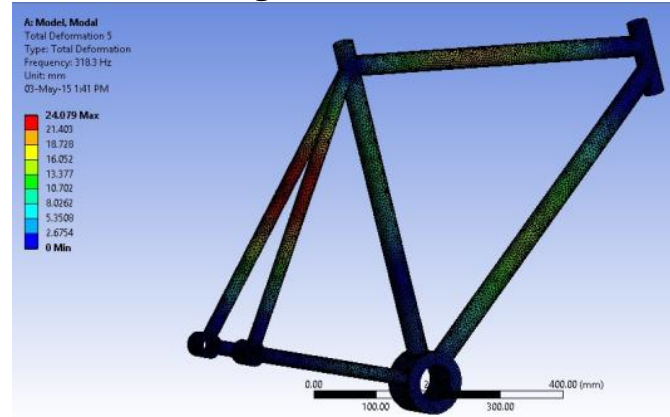

Figure 25: Mode 5, $318.3 \mathrm{~Hz}$

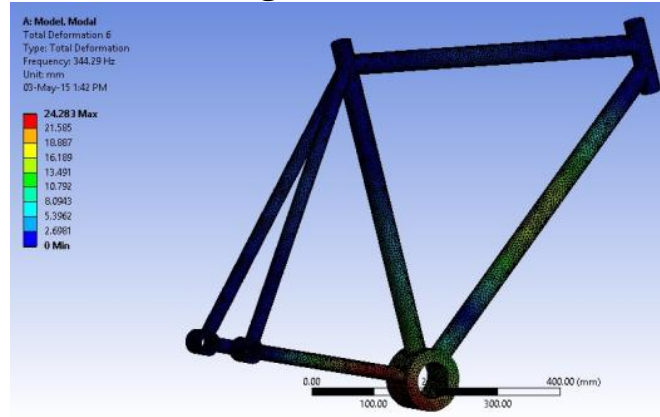

Figure 26: Mode 6, 344.29 Hz

3.5 Titanium-6Al-4V

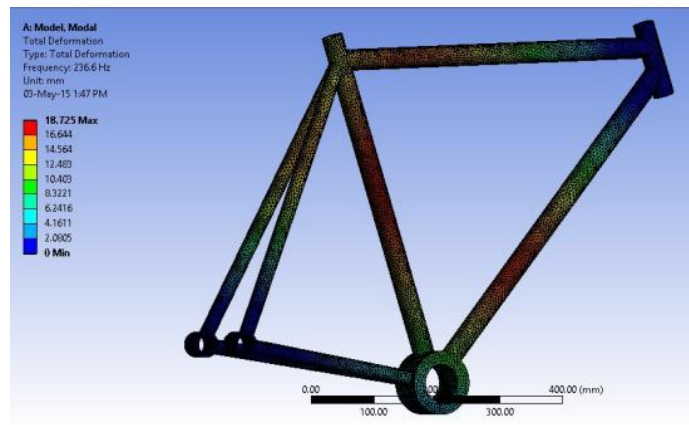

Figure 27: Mode 1, 236.6 Hz

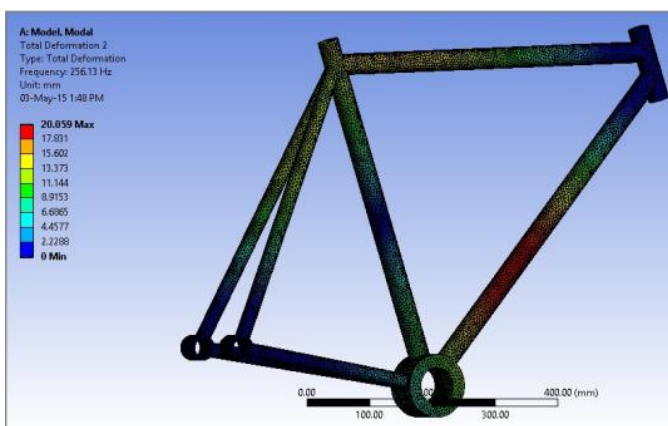

Figure 28: Mode 2, 256.13 Hz

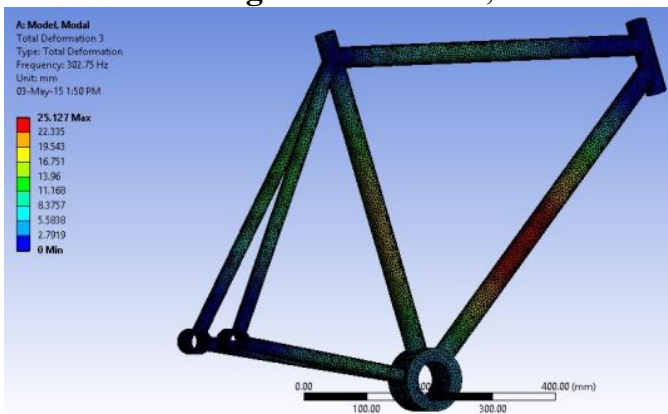

Figure 29: Mode 3, $302.75 \mathrm{~Hz}$

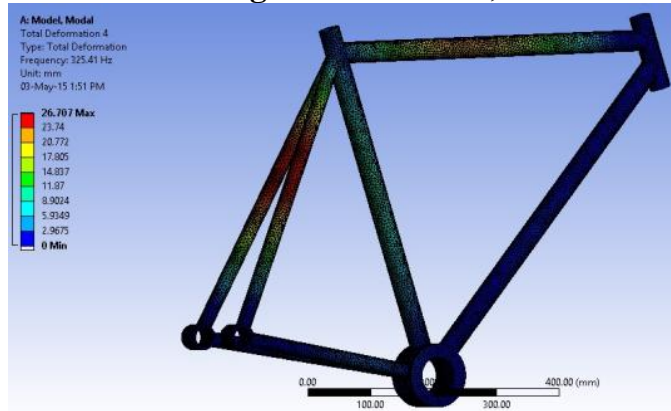

NW
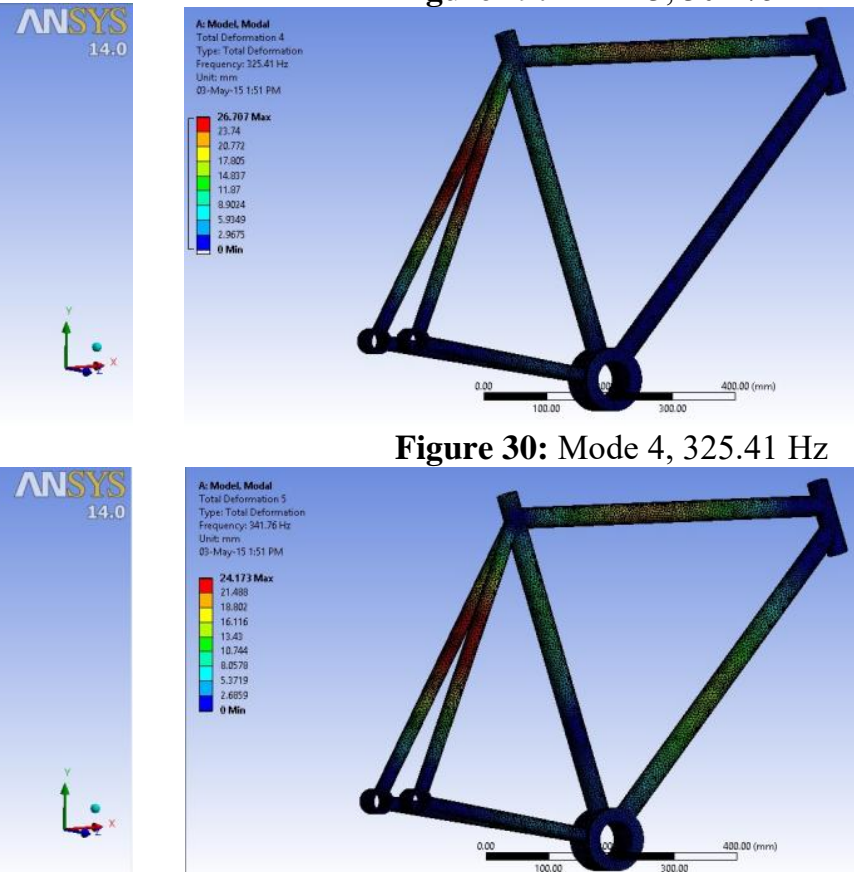

MN

Figure 31: Mode 5, $341.76 \mathrm{~Hz}$

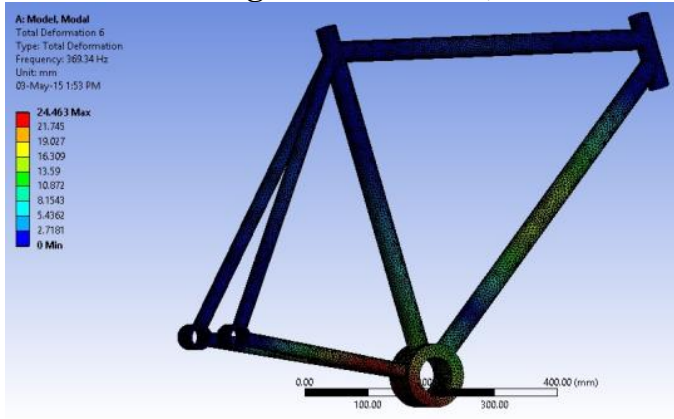

Figure 32: Mode 6, $369.34 \mathrm{~Hz}$

Volume 6 Issue 1, January 2017 www.ijsr.net 


\section{International Journal of Science and Research (IJSR)}

ISSN (Online): 2319-7064

Index Copernicus Value (2015): 78.96 | Impact Factor (2015): 6.391

\section{Result and Conclusion}

Table 2: Comparison of natural frequencies of the bike frames $(\mathrm{Hz})$

\begin{tabular}{|c|c|c|c|c|c|c|}
\hline \multirow{2}{*}{ ALLOYS } & \multicolumn{5}{|c|}{ Natural frequency of the bike frames (Hz) } \\
\cline { 2 - 7 } & Mode 1 & Mode 2 & Mode 3 & Mode 4 & Mode 5 & Mode 6 \\
\hline $\begin{array}{c}\text { Aluminum } \\
6061-\mathrm{T}\end{array}$ & 235.78 & 255.27 & 301.66 & 324.36 & 340.54 & 368.11 \\
\hline $\begin{array}{c}\text { Aluminum } \\
7005-\mathrm{T}\end{array}$ & 235.86 & 255.37 & 301.71 & 324.53 & 340.61 & 368.27 \\
\hline $\begin{array}{c}\text { Chromoly- } \\
\text { 4130 }\end{array}$ & 238.44 & 258.23 & 304.91 & 328.3 & 344.23 & 372.41 \\
\hline $\begin{array}{c}\text { Titanium-3Al- } \\
\text { 2.5V }\end{array}$ & 220.46 & 238.73 & 281.95 & 303.48 & 318.3 & 344.29 \\
\hline $\begin{array}{c}\text { Titanium-6Al- } \\
\text { 4V }\end{array}$ & 236.6 & 256.13 & 302.75 & 325.41 & 341.76 & 369.34 \\
\hline
\end{tabular}

The modal analysis clearly suggests the dynamic behavior of the bike frames on free vibration conditions. The mode shapes quantify the vibrational pattern of the material alloy. The 1st mode shape obtained defines the 1st vibration obtained for the bike frame on free vibration. From Table 50 we can deduce the mode shape obtained for different alloys. The increasing order of frequency is as follows:

Titanium-3Al-2.5V < Aluminum 6061-T < Aluminum 7005-T $<$ Chromoly-4130 $<$ Titanium-6Al-4V

The increasing order of deformation can be made out from the figure (124-154) which is as follows:

Chromoly-4130 < Titanium-3Al-2.5V < Titanium-6Al-4V $<$ Aluminum7005-T < Aluminum 6061-T

\section{References}

[1] M.V.Pazare et al. / International Journal of Engineering Science and Technology (IJEST), ISSN: 0975-5462, Vol. 6 No.6 Jun 2014.

[2] Patrick L. Lizotte, (1996), Stress analysis and fabrication of composite monoque bicycle frames, Department of Mechanical Engineering, McGill University, Montréal

[3] Peterson, L., Londry, K., 1986. Finite-Element Structural Analysis: A New Tool for Bicycle Frame Design: The Strain Energy Design Method.

[4] Reynolds Technology Ltd. 2011a. Steel tube materials and processes.

[5] Reynolds Technology Ltd. 2011b.eReynolds Manual for eReynolds software.

[6] Soden, P., Adeyefa, B. 1979. Forces applied to a bicycle during normal cycling. Journal of Biomechanics 12, 527-541.

[7] Stone, C, and Hull, M. L., 1995, "The Effect of Rider Weight on Rider-Induced

[8] Loads During Common Cycling Situations," Journal of Biomechanics, Vol. 28, pp. 365-375.

[9] William David Nadir, 2005, Multidisciplinary Structural Design and Optimization for Performance, Cost, and Flexibility, Department of Aeronautics and Astronautics, Massachusetts institute of Technology.

[10] Xiang, Z., Xu, R., Bu, Y., Wu, X., 2011. Optimal Design of Bicycle Frame Parameters Considering
Biomechanics. Chinese Journal of Mechanical Engineering, vol 24, 1-5.

[11] Xie, Y., Steven, G., 1994. Optimal design of multiple load case structures using an evolutionary procedure. Engineering Computations 11(4), 295 - 302.

[12] Gupta Rajeev, Seshagiri Rao G.V.R., Analysis of All Terrain Bike Frame by F.E.M. e-ISSN: 2278-1684,pISSN: 2320-334X, Volume 13, Issue 2 Ver. II.

[13] Dwyer Forrest, Shaw Adrian, Tombarelli Richard 2012 Material and Design Optimization for Aluminum Bike Frame, WORCESTER POLYTECHNIC INSTITUTE.

[14] R.K.Bansal, "Strength of Materials: Mechanics of solid”, Laxmi Publications New Delhi. 